\title{
Microwave Surface Resistance of Reactively Sputtered NbN Thin Films
}

\author{
J. J. Bautista \\ Radio Frequency and Microwave Subsystems Section \\ D. M. Strayer \\ Microgravity and Flight Experiments Research Section
}

\begin{abstract}
The surface resistance of niobium nitride $(\mathrm{NbN})$ thin films has been measured at 7.78 and $10.14 \mathrm{GHz}$ in the temperature range of 1.5 to $4.2 \mathrm{~K}$. The films were reactively sputtered on sapphire substrates to a thickness of approximately 1 micron. The surface resistance was determined by measuring the quality factor $(Q)$ of the $T E_{011}$ mode of a lead-plated copper cavity where the $N b N$ served as one end-cap of the cavity.
\end{abstract}

\section{Introduction}

Although the B1 and A15 superconductors are of primary interest for the development of active devices (Josephson junction and SIS devices), homogenous, high critical temperature $\left(T_{c}\right)$ superconductors are also of interest for passive microwave device applications. Dissipative losses and interfering signals can significantly increase the noise temperature of cryogenic ultra-low noise microwave amplifiers such as masers (Ref. 1) and High Electron Mobility Transistor (HEMT) amplifiers (Ref. 2). Microstrip and stripline superconducting filters and transmission lines can provide protection without significantly increasing the amplifier noise temperature (Ref. 3). Furthermore, the widespread availability of relatively inexpensive commercial, close-cycle refrigerators (10- to $15-\mathrm{K}$ operating range) will readily allow the integration of high $T_{c}$ superconducting devices with HEMTs.
For temperatures below $4.2 \mathrm{~K}$, high $T_{c}$ resonant structures can significantly improve the performance of maser amplifiers and cavity-stabilized oscillators. In a traveling wave maser (TWM) amplifier, dissipative losses in the slow-wave structure limit the amplifier noise temperature and gain. A superconducting slow-wave structure having a high second critical magnetic field would allow the construction of a TWM amplifier with near theoretical response, lowering the noise temperature by as much as 50\% and increasing the gain bandwidth product by as much as $100 \%$. The long-term frequency stability of a superconducting cavity-stabilized oscillator (SCSO) relies on the high $Q$ and good mechanical stability of the superconducting cavity. A high $T_{c}$ superconductor deposited on a sapphire substrate to form a superconducting cavity would allow operation of the oscillator at a higher temperature. For example, for a cavity having a $Q$ of $10^{9}, 10^{-17}$ stability can be obtained using a lead film only by cooling to 
$0.9 \mathrm{~K}$, while an $\mathrm{NbN}$ cavity would allow operation at $2 \mathrm{~K}$ (Ref. 4). Both these systems place requirements on the surface resistance of the superconducting film at microwave frequencies.

Surface resistance measurements can also serve as a deposition process monitor and as a non-destructive means of evaluating the homogeneity and quality of the film (Refs. 5 and 6). This work was initiated to determine the feasibility of the B1 compound $\mathrm{NbN}$ for passive microwave applications, since it can be fabricated with relative ease and, in addition, good quality thin films have been demonstrated using various deposition methods (Refs. 7, 8, and 9). This article presents the preliminary results of measurements of the surface resistance of $\mathrm{NbN}$ at $\mathrm{X}$-band frequencies.

\section{Sample Preparation}

The $\mathrm{NbN}$ thin films were dc-magnetron sputtered at an approximate rate of $1700 \mathrm{~A} / \mathrm{min}$ onto flat sapphire substrates to a thickness of about $1 \mathrm{micron}$. Throughout the deposition, the nitrogen partial pressure was maintained at $0.57 \mathrm{~Pa}$ and the argon at $1.56 \mathrm{~Pa}$. The deposition was initiated with the substrates at room temperature and no attempt was made to control the substrate temperature during the deposition.

The epi-finished sapphire substrates were purchased from Insaco, Inc. (Quakertown, Penn.). Before the deposition, the substrates were cleaned with soapy de-ionized water and then rinsed in de-ionized water. The substrates were then degreased by rinsing them in acetone $(5 \mathrm{~min})$, methanol $(5 \mathrm{~min})$, and freon $(5 \mathrm{~min})$.

A variety of sample sizes were deposited for three different experiments. Three $5-\mathrm{cm}$ diameter wafers (two 0.025 - and one $0.300-\mathrm{cm}$ thick) were made for the $Q$-cavity measurements presented in this report. A second set of four rectangular samples $(7.00$ by 2.03 by $0.064 \mathrm{~cm}$ ) were made for calorimetric surface resistance measurements (Ref. 10). The third set of rectangular samples (four 9.40 by 0.56 by $0.076 \mathrm{~cm}$ and four 12.7 by 2.13 by $0.152 \mathrm{~cm}$ ) were saved for slow-wave structure patterning and subsequent insertion loss measurements.

\section{Microwave Measurements}

The two cylindrical X-band cavities used for the $Q$ measurements were made of OFHC copper electroplated with lead to a thickness of approximately 3 microns (Ref. 11). The cavities have diameter to length ratios of 1.0 and 1.75 , and were operated in the $\mathrm{TE}_{011}$ mode at 7.78 and $10.14 \mathrm{GHz}$, respectively. The cavity $Q$ 's were all determined by pulsing the incident microwave energy and measuring the decay time of the stored cavity energy (Ref. 12). For these measurements, the homogeneous $\mathrm{Pb}(\mathrm{Cu})$ cavities were first characterized as a function of temperature and the surface resistance $\left(R_{s}\right)$ was determined using the following expression:

$$
R_{s}=\frac{G}{Q_{0}}
$$

where $G$ is a geometrical factor (780 and 619 ohms, respectively, for the present geometries) and $Q_{0}$ is the baseline quality factor for the $\mathrm{Pb}(\mathrm{Cu})$ surface only.

The surface resistance at $7.78 \mathrm{GHz}$ of samples 1 and 2 ( $\mathrm{NbN}$ on 0.025 -cm-thick substrates) was determined by placing them on top of the bottom end-cap of the cavity and repeating the decay time measurements. At $10.14 \mathrm{GHz}$, sample $3(\mathrm{NbN}$ on $0.300-\mathrm{cm}$ thick substrate) replaced the removable $\mathrm{Pb}(\mathrm{Cu})$ end-cap. For this cavity configuration, the relationship between the surface resistance of the thin-film end-cap $\left(R_{x}\right)$ and the measured quality factor, $Q_{x}$, is given by the following expression:

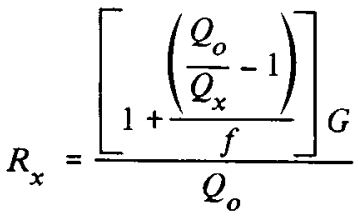

where $f(0.072$ and 0.206 , respectively) is the fraction of the total cavity loss associated with the thin-film end-cap.

\section{Experimental Results and Discussion}

The results at $7.78 \mathrm{GHz}$ for samples 1 and 2 are plotted in Fig. 1. Included for comparison are the Stanford calorimetric data (Ref. 10) for sample 4 at $8.6 \mathrm{GHz}$. Although the $Q$-cavity and calorimetric cavity data appear to be in agreement at temperatures near $4 \mathrm{~K}$, the measured results for samples 1 and 2 show lots of scatter and appear to be temperature independent. Since samples 1 and 2 rest on top of the cavity end-cap, it is strongly suspected that inadequate heat contact with the helium bath resulted in the observed thermal heating effects. To obviate this latter difficulty, the $10.14-\mathrm{GHz}$ cavity was constructed so that it would accept sample 3 as the end-cap. This configuration results in a sample that is in direct contact with the helium bath. Figure 2 contains a plot of the results for $\mathrm{NbN}$ sample 3, along with the data for the $\mathrm{Pb}(\mathrm{Cu})$ at $10.14 \mathrm{GHz}$. Both sets of data clearly exhibit a strong temperature dependence; however, the expected (BCS) precipitous drop in surface resistance is absent. 
The data for sample 3 was fit by linear regression to a linearized form of the BCS surface resistance for $T<0.5 T_{c}$ given by:

$$
R_{s}(T)=A \exp \left[-e_{g}\left(\frac{T_{c}}{T}\right)\right]+R_{o}
$$

where $R_{o}$ is a residual surface resistance, $e_{g}$ is the normalized zero temperature energy gap parameter, and $T_{c}$ is the critical transition temperature. Figure 3 contains a plot of the best fit to the data of sample 3 , assuming $T_{c}=15.2 \mathrm{~K}$ and $R_{o}=$ 10 micro-ohms. The resulting 0.52 value of $e_{g}$ is a factor of one half smaller than the smallest values determined from tunneling measurements (Ref. 9).

Although the $e_{g}$ value for $\mathrm{NbN}$ sample 3 is anomalously small, it is in agreement with the results obtained by Isagawa at $6.5 \mathrm{GHz}$ on samples of $\mathrm{NbN}$ reactively sputtered on $\mathrm{Nb}$ (Ref. 13). But in contrast to the NbN results, the linear regression analysis for the 7.78 - and $10.14-\mathrm{GHz} \mathrm{Pb}(\mathrm{Cu})$ cavity measurements yielded $e_{g}$ values of 1.98 and 2.00 , respectively, which are approximately $10 \%$ less than the tunneling measurement values (Ref. 14).

The large difference between the $e_{g}$ values determined by RF measurements and those determined by dc tunneling mea- surements is believed to be associated with the columnar structure of sputtered $\mathrm{NbN}$ and the compounds that form between the $\mathrm{NbN}$ and the $10 \mathrm{~A} \mathrm{Nb}_{2} \mathrm{O}_{5}$ outermost layer. The smaller $e_{g}$ value obtained from RF measurements is the result of the formation of a metallic $\mathrm{NbN}$ suboxide with a $T_{c}$ of approximately $7 \mathrm{~K}$ adjacent to the serrated $\mathrm{NbN}$ (Ref. 15). The dc tunneling currents flow directly across the serrated peaks of $\mathrm{NbN}$, while $\mathrm{RF}$ currents are induced in both the $\mathrm{NbN}$ and the lossier $\mathrm{NbN}$ suboxide, resulting in an averaged lower $e_{g}$.

\section{v. Conclusions}

In Fig. 1, for comparison to a normal metal, the surface resistance is plotted for OFHC Cu, calculated from the insertion loss measurements as a function of temperature for an interdigital filter. Comparison of this $\mathrm{Cu}$ data with the calorimetric data shows that below $12 \mathrm{~K}$, the $\mathrm{NbN}$ surface resistance is at least $1 / 10$ th the value of $\mathrm{Cu}$. Future planned insertion loss measurements of $\mathrm{NbN}$ slow-wave structures at 2.3 and $8.4 \mathrm{GHz}$ subjected to large dc magnetic fields will determine the applicability of $\mathrm{NbN}$ to TWMs. Although the question regarding the applicability of $\mathrm{NbN}$ for SCSOs remains unresolved, it is evident that this material is clearly applicable for microstrip and stripline devices operating in the 10 - to $15-\mathrm{K}$ temperature range.

\section{References}

1. Bautista, J. J., and Petty, S. M., "Cryogenic Filters for RFI Protection," TDA Progress Report 42-65, p. 94, July-August, 1981.

2. Pospieszalski, M. W., Weinreb, S., Chao, P. C., Mishra, U. K., Palmeter, S. C. Smith, P. M., and Hwang, J. C. M., "Noise Parameters and Light Sensitivity of Low-Noise HEMTs at 300 and $12.5 \mathrm{~K}$," IEEE Trans. Electron Devices, ED-33, pp. 218-223, February 1986.

3. Bautista, J. J., and Petty, S. M., "Superconducting $\mathrm{NbTi}$ and $\mathrm{Pb}(\mathrm{Cu})$ Bandpass Filters," IEEE Trans. Magn. MAG-21, No. 2, pp. 640-643, 1985.

4. Strayer, D. M., Dick, G. J., and Mercereau, J. E., "Performance of a Superconducting Cavity Stabilized Ruby Maser Oscillator," Applied Superconductivity Conference Paper No. MH-4, 1986 Applied Superconductivity Conference, September 29October 3, 1986.

5. Allen, L. H., Beasley, M. R., Hammond, R. H., and Turneaure, J. P., "RF Surface Resistance of High $\mathrm{T}_{c}$ Superconducting A15 Thin Films," IEEE Trans. Magn., MAG.21, No. 3, p. 1003, 1983. 
6. Allen, L. H., Anklam, W. J., Beasley, M. R., Hammond, R. H., and Turneaure, J. P., "RF Surface Resistance in $\mathrm{Nb}_{3} \mathrm{Sn}$ Thin Films," IEEE Trans. Magn., MAG-21, No. 2, pp. 525-527, 1985.

7. Villegier, J. C., Vieux-Rochaz, L., Goniche, M., Renard, P., and Vabre, M., "NbN Tunnel Junctions," IEEE Trans. Magn., MAG-21, No. 2, pp. 498-504, 1985.

8. Gurvitch, G., Remekia, J. P., Rowell, J. M., Geerk, J., and Lowe, W. P., "Tunneling, Resistive and Structural Study of NbN and Other Superconducting Nitrides," IEEE Trans. Magn., MAG-21, No. 2, pp. 509-513, 1985.

9. Bacon, D. D., English, A. T., Nakahara, S., Peters, F. G., Schreiber, H., Sinchair, W. R., and van Dover, R. B., "Properties of NbN Thin Films Deposited on Ambient Temperature Substrates," J. Applied Phys., 54, pp. 6509-6516, 1983.

10. Allen, L. H., Beasley, M. R., and Turneaure, J. P., "RF Surface Resistance of $\mathrm{Nb}_{3} \mathrm{Sn}$, $\mathrm{NbZr}$, and NbN Thin Films," ASC Paper No. MG-20, 1986 Applied Superconductivity Conference, September 29-October 3, 1986.

11. Dick, G. J., and Delayen, J. R., "A New Chemical Polishing Procedure for LeadPlated Copper Superconducting Accelerating Resonators," IEEE Trans. Magn., $M A G-19$, No. 3, 1983.

12. Yogi, T., Radio Frequency Studies of Surface Resistance and Critical Magnetic Field of Type I and Type II Superconductors, Ph.D. Thesis, California Institute of Technology, 1977.

13. Isagawa, S., "RF Superconducting Properties of Reactively Sputtered NbN," $J$. Applied Phys., 52, pp. 921-927, 1981.

14. Kittel, C., Introduction to Solid State Physics, 5th Ed., John Wiley and Sons, NY, NY, pp. 412-413, 1976.

15. Halbritter, J., "Superconductivity of Oxidized NbN Compound Surfaces," $A S C$ Paper No. MC-11, 1986 Applied Superconductivity Conference, September 29October 3, 1986. 


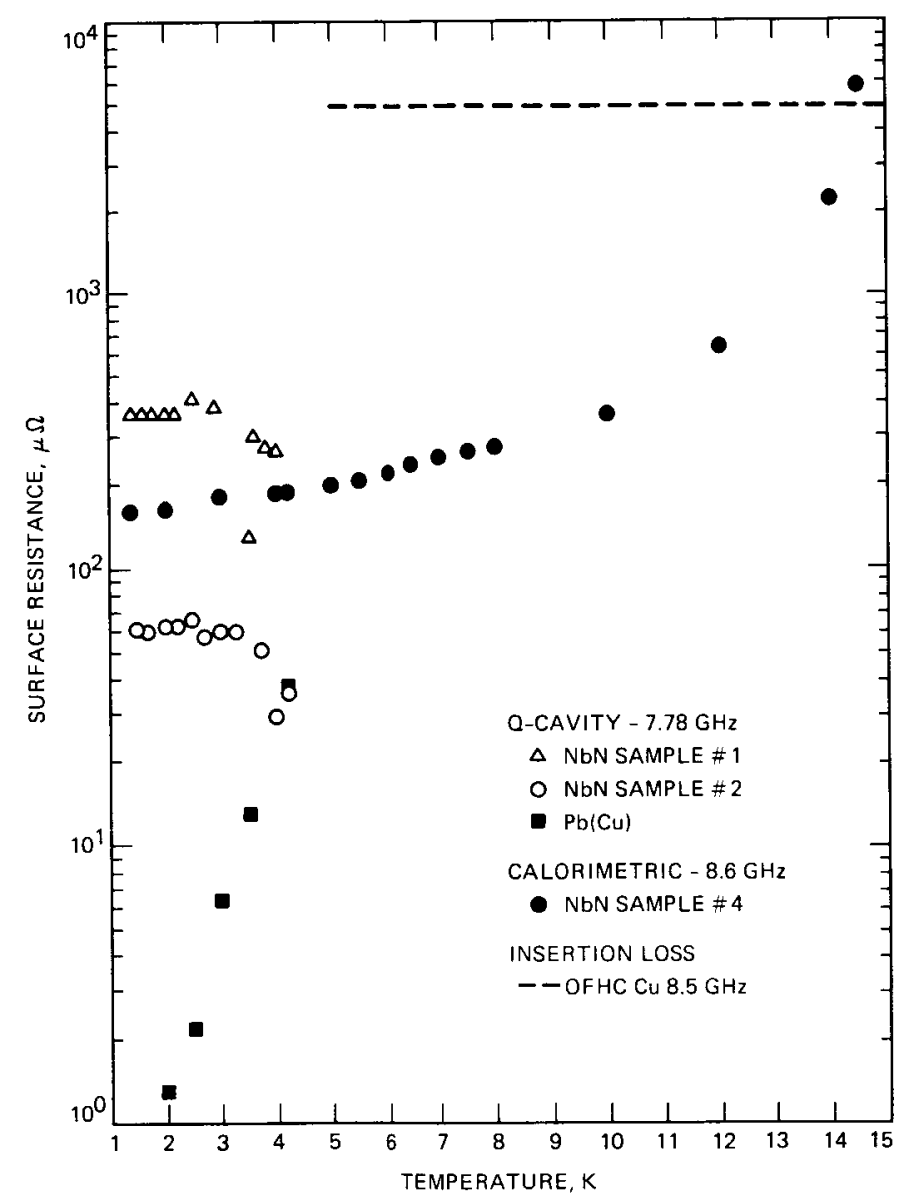

Fig. 1. Surface resistance measurements of NbN samples at 7.78 and $8.6 \mathrm{GHz}$

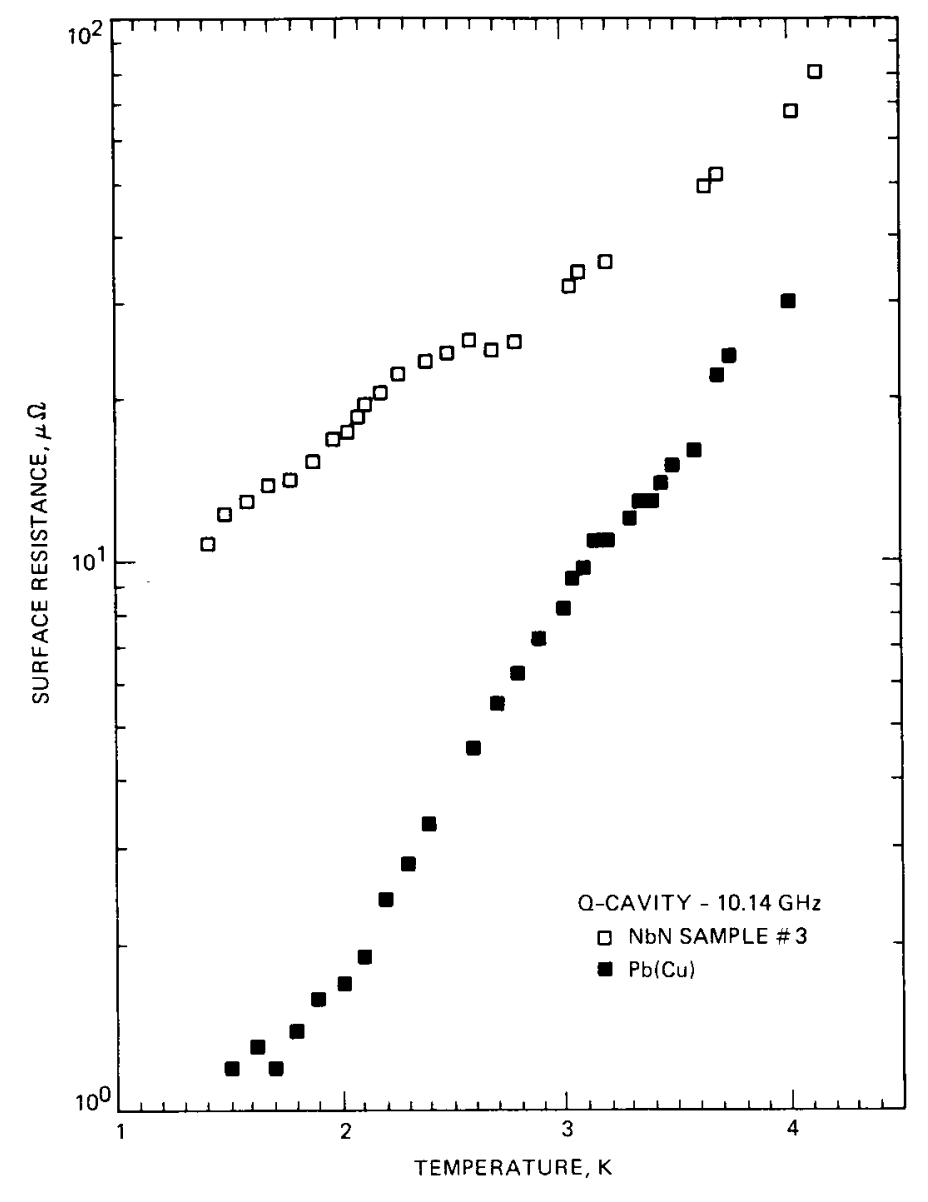

Fig. 2. NbN surface resistance measurements at $10.14 \mathrm{GHz}$

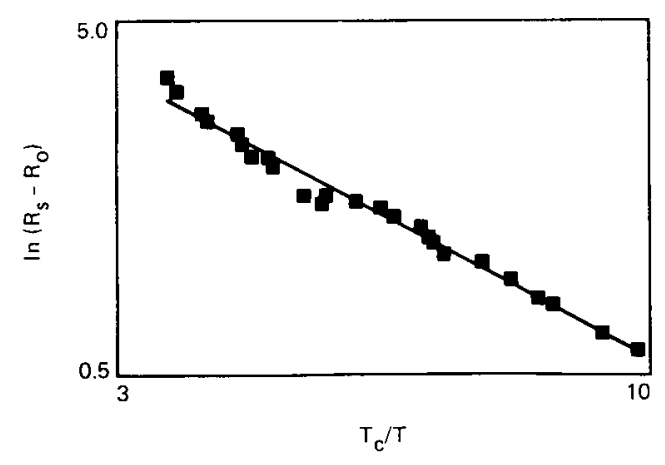

Fig. 3. Linear regression fit to sample 3 